\title{
TU/e EN⿴HONE

\section{Simulating the influence of life trajectory events on transport mode behavior in an agent-based system}

\section{Citation for published version (APA):}

Verhoeven, M., Arentze, T. A., Timmermans, H. J. P., \& Waerden, van der, P. J. H. J. (2007). Simulating the influence of life trajectory events on transport mode behavior in an agent-based system. In Proceedings of the 10th IEEE Conference on Intelligent Transportation Systems (ITSC 2007) 30 Sept - 3 October 2007, Seattle, Washington, USA (pp. 107-112). Institute of Electrical and Electronics Engineers.

https://doi.org/10.1109/ITSC.2007.4357815

DOI:

10.1109/ITSC. 2007.4357815

Document status and date:

Published: 01/01/2007

\section{Document Version:}

Publisher's PDF, also known as Version of Record (includes final page, issue and volume numbers)

\section{Please check the document version of this publication:}

- A submitted manuscript is the version of the article upon submission and before peer-review. There can be important differences between the submitted version and the official published version of record. People interested in the research are advised to contact the author for the final version of the publication, or visit the $\mathrm{DOI}$ to the publisher's website.

- The final author version and the galley proof are versions of the publication after peer review.

- The final published version features the final layout of the paper including the volume, issue and page numbers.

Link to publication

\section{General rights}

Copyright and moral rights for the publications made accessible in the public portal are retained by the authors and/or other copyright owners and it is a condition of accessing publications that users recognise and abide by the legal requirements associated with these rights.

- Users may download and print one copy of any publication from the public portal for the purpose of private study or research.

- You may not further distribute the material or use it for any profit-making activity or commercial gain

- You may freely distribute the URL identifying the publication in the public portal.

If the publication is distributed under the terms of Article 25fa of the Dutch Copyright Act, indicated by the "Taverne" license above, please follow below link for the End User Agreement:

www.tue.nl/taverne

Take down policy

If you believe that this document breaches copyright please contact us at:

openaccess@tue.nl

providing details and we will investigate your claim. 


\title{
Simulating the Influence of Life Trajectory Events on Transport Mode Behavior in an Agent-based System
}

\author{
Marloes Verhoeven, Theo Arentze, Harry Timmermans, and Peter van der Waerden \\ (Eindhoven University of Technology)
}

\begin{abstract}
- this paper describes the results of a study on the impact of lifecycle or life trajectory events on activity-travel decisions. This lifecycle trajectory of individual agents can be easily incorporated in an agent-based simulation system. This paper focuses on two lifecycle events, change in residential location and change in number of household members. An Internet-based survey was designed to collect data concerning structural lifecycle events. Previous papers describe the conceptual framework underlying the model and the temporal effects of lifecycle events on mode choice. This paper focuses on predicting the occurrence of structural lifecycle events at a certain time. Structure and parameter learning are applied to build a Bayesian Belief Network based on the data.
\end{abstract}

\section{INTRODUCTION}

$\mathrm{R}$ ECENTLY, several agent-based simulation systems have been developed in the transportation literature for a multitude of applications. Original models were often concerned with the simulation of traffic flows, using the carfollowing principle. Later this work was extended to problems of activity program generation [1], and implemention and simulation of activity-travel agendas or plans [2] - [9].

This apparent focus on short-term dynamics however covers only a limited set of activity-travel dynamics. It is quite common nowadays in the transportation literature to differentiate between short term, sometimes mid-term, and long-term dynamics. The latter topic is concerned with the impact of lifecycle or life trajectory events on activity-travel decisions. Because many activity-based models of transport demand are based on a synthetic population of inviduals anyhow, the lifecycle trajectory of individual agents can be easily incorporated in an agent-based simulation system.

As part of a wider project which examines the impact of lifecycle events on activity-travel decisions (especially transport mode choice), this paper discusses the conceptual framework, modelling approach and some first results of such an agent-based model of transport demand dynamics. First, we will briefly discuss the conceptual framework underlying the approach. Next, we will discuss how Bayesian networks are used to represent the impact of

\footnotetext{
Manuscript received August 15, 2007.

Marloes Verhoeven, Theo Arentze, Harry and Peter van der Waerden are with the Urban Planning Group, Timmermans Eindhoven University of Technology, the Netherlands (phone corresponding author: 040-2472934; general fax number: 040-2438488; e-mail: m.verhoeven@bwk.tue.nl, t.a.arentze@bwk.tue.nl; h.j.p.timmermans@bwk.tue.nl; p.j.h.j.v.d.waerden @bwk.tue.nl).)
}

lifecycle events on transport mode choice decisions and discuss some results. Finally, we will briefly explain the larger context by articulating how these results can be embedded into the large-scale simulation model.

\section{CONCEPTUAL CONSIDERATIONS}

Based on earlier work by the authors [10], [11], [19] we assume that individuals, represented as agents in the system, adapt their behavior such that, given a set of constraints, the utility derived from the outcomes of their behavior meets at least a certain aspiration level. Under stationary conditions, after some period of time, agents will show habitual behavior, at least for a particular set of environmental conditions [22].

We assume that changes in behavior come about when a discrepancy between aspiration and actual utilities beyond some threshold will trigger agents to explore new alternatives, which in turn may lead to changes in behavior. Many factors may cause such discrepancy: the travel environment may change; agent needs may change, etc. Waerden, Borgers and Timmermans [11] identified two important factors: critical incidents, unexpected events such as accidents or unexpected long delays which may cause agents to reconsider their habitual behavior, and lifecycle events, such as the birth of a child, change of job, etc. In the latter case, the discrepancy is increased because the set of conditions influencing optimal travel choice has (dramatically) changed (responsive behavior) or is expected to change dramatically (anticipated behavior).

We assume that an agent is likely to reconsider his/her current mode choice after the occurrence of a lifecycle event. Through search an agent explores choice opportunities in his or her environment and keeps a memory record of the varying rewards associated with his actions. Actions that produce positive rewards are reinforced and have a higher probability of being repeated in future choice situations under similar conditions, while actions with negative outcomes tend to be avoided. In stationary environments, reinforcement learning implies that random behavior will ultimately evolve into habitual behavior. In non-stationary environments, discrepancies between the changing environments and changing personal or household circumstances may imply that the behavior of interest is no longer adequate to cope with the new situation. An individual may then have to change one or more facets of 
his habitual behavior. Structural lifecycle events may have a similar, but attenuated effect. A dilemma for any individual, who has limited knowledge about new circumstances, is the choice between exploration and exploiting current knowledge. Selecting actions that have not been tried before gives the opportunity of discovering new choices that may yield higher rewards than the currently best action. However, this comes with the risk of negative experiences. Individuals who wish to avoid such risks may stick to the currently best choice. Thresholds for reconsidering current choices and the thoroughness of search will vary depending on the individual's tendency to take or avoid such risks.

\section{BAYESIAN BELIEF NETWORKS}

A Bayesian network is used to represent and simulate the direct and indirect effects of life trajectory events on transport mode choice decisions. The potential advantage of $\mathrm{BBN}$ over BDI architecture is that more complex causation patterns may be included and morever learning can be easier accommodated. Bayesian networks are directed acyclic graphs (DAGs) in which the nodes represent variables, the arcs signify the existence of direct causal influences between the linked variables, and the strengths of these influences are expressed by the forward conditional probabilities [12]. Each node has an underlying conditional probability table (CPT) that describes the chance distribution across the states of that specific node for each possible combination of states of the parent nodes.

A Bayesian network is denoted by $B(G, \Theta)$, in which $G$ $(N, A)$ is a DAG where $N$, the set of nodes, represents a set of variables $X=\left\{X_{1}, X_{2}, \ldots, X_{n}\right\}$ and $A$ is a set of arcs representing the directed dependency relationships from parent nodes to child nodes, and $\Theta$ denotes a set of CPTs associated with the node set $N$ and the arc set $A$, where $\theta_{i} \in$ $\Theta$, where $i .1,2, \ldots, n$, is the CPT of variable $X_{i}, \theta_{i}=\mathrm{P}\left(X_{i}\right.$ $\Pi_{\mathrm{i}}$ ), given the parent variable set $\Pi_{\mathrm{i}}$ of $X_{i}$. In a given Bayesian network $B$, marginal and conditional independencies encoded by its DAG structure provide the following factorization of the joint probability distribution:

$$
P\left(X_{1}, X_{2}, \ldots, X_{n}\right)=\prod_{i=1}^{n} P\left(X_{i} \mid \prod_{i}\right)
$$

Standard algorithms can be used to compile the network and determine the expected belief of each node state. Using the same algorithms, beliefs can be updated when evidence for certain nodes becomes available and is entered into the network. The BBN can handle uncertainty, in other words it can calculate the beliefs for several states. If evidence for a certain node becomes available it can be entered in the network and all the beliefs will be updated automatically.

\section{LEARNING NETWORKS}

Until now we assumed that the structure and conditional probabilities necessary for characterizing the network were provided externally, say by an expert or an intelligent agent capable of encoding real-world experience in such terms. It is not always easy to construct a complicated network based on the literature and/or common knowledge. Fortunately, nowadays, methods are available that support the derivation of a network automatically from empirical observations, thus bypassing the human link in the process known as knowledge acquisition.

Pearl [12] describes that the task of finding a generic model of emperical data usually falls under the category of learning. Learning can be thought of as the process of acquiring an effective internal representation for the persistent constraints in the world, i.e., generic facts and rules, as well as assembling the computational facilities by which predictions and explanations are produced. Learning is comprised of two subtasks; structure learning and parameter learning. Taking Bayesian belief networks as the basic scheme of knowledge representation, the learning task seperates nicely into two additional subtasks; learning the numerical parameters (i.e., the conditional probabilities) for a given network topology and identifying the structure itself, specifically, the links and the directionality of the arrows. These subtasks are clearly not independent because the set of parameters needed depends largely on the structure assumed, and conversely, the structure of the network is formally dictated by the joint distribution. Still, it is more convenient to execute the learning process in two separate phases: structure learning and parameter learning.

Hugin, a software program for learning Bayesian networks [13], uses the PC or NPC algorithm for structure learning and the EM algorithm (Estimation-Maximalisation) for parameter learning. The PC algorithm, which Hugin uses, is a variant of the original PC algorithm [14] and it belongs to the class of constraint-based learning algorithms. The basic idea of these algorithms is to derive a set of conditional independence and dependence statements by statistical tests. The PC algorithm consists of the five following steps [14], [15]:

The main steps of the PC algorithm are:

1. Test for (conditional) independence between each pair of variables.

2. Identify the skeleton of the graph induced by the derived conditional independence and dependence relations (CIDRs).

3. Identify colliders.

4. Identify derived directions.

The first two steps are repeated until all the possible pairs are tested. First only pairs are tested (no conditional relations), after that pairs are tested conditional on a third variable and so on until all pairs are tested conditional. The following independence testing procedure is used for the first step in the PC algorithm: If variable $X$ causes variable $Y$, it implies a probabilistic dependency, $P(Y \mid X) \neq P(Y)$. Thus, if the null hypothesis of marginal independence of $X$ and $Y, H_{0}: P(Y \mid X)=P(Y)$ or $P(X, Y)=P(X) P(Y)$ is rejected, the directed dependence $X \rightarrow Y$ is supported. 
One important thing to note about the $\mathrm{PC}$ algorithm is that, in general, it will not be able to derive the direction of all the links from data, and thus some links will be directed randomly. This means that the learned structure should be inspected, and if any links seem counterintuitive the NPC algorithm (Necessary Path Condition [21]), which allows the user to interactively decide on the directionality of undirected links, could be used instead. Another possibility is to import constraints in the structure learning process. Constraints describe where no directed or undirected link could appear.

The NPC algorithm seeks to repair the deficiencies of the PC algorithm. The solution provided by the NPC algorithm is based on inclusion of a criterion known as the Necessary Path Condition. This criterion forms the basis for introducing the notion of ambiguous regions, which in turn provide a language for selecting among sets of interdependent uncertain links. The resolution of ambiguous regions is performed in interaction with the user. To resolve the inconsistencies, the NPC algorithm relies on user interaction where the user gets the opportunity to decide on directionality of undirected links and to resolve the ambiguous regions.

The EM algorithm [16], [17] tries to find the model parameters (conditional probability distributions) of the network from observed (but often not complete) data that maximizes the log-likelihood of the current joint probability distribution on the case data (for details of the method readers are referred to [16], [17]).

\section{MODELING APPROACH}

We assume that a structural lifecycle event changes a certain personal situation, i.e., state. Besides the assumption that a structural lifecycle event changes a person or household-level state, we also assume that events may influence each other. When an individual starts with a new job in a different location he/she might consider moving to that new location soon or late. In that case the occurrence of a change in work location could trigger a change in residential location. Another example of influences between structural lifecycle events is a possible effect of a change in work, for example promotion on the income.

There are three types of variables in our general conceptual model (Fig. 1): (1) Personal Characteristics, such as Gender (node A) and Age (B), (2) Mode Choice (C) and (3) variables related to Structural Lifecycle Events (set of nodes within the rectangles). The first two types of variables are also referred to as external variables. The model could be extended with more structural lifecycle events. First, we explain the variables related to structural lifecycle events. The variables are defined with respect to a certain moment in time, $t$, a certain person and a certain event (using some classification of events) for which the model intends to predict whether or not a change occurred as a particular instance of an event of that type. The node Occurrence

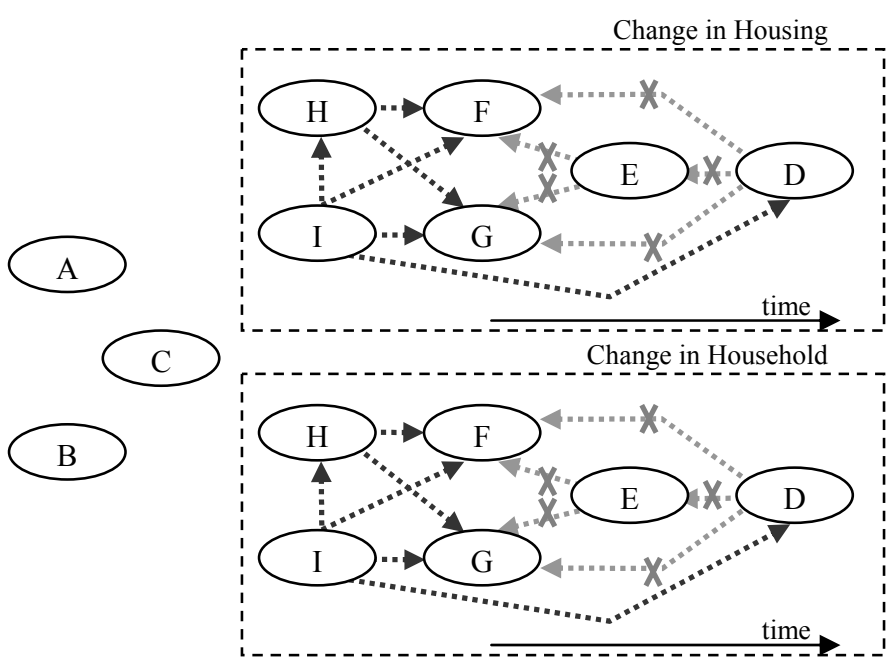

Fig. 1: Conceptual Model

Event (D) defines if there was a change at time $t$ for that certain event and what kind of change it was. The existing state before time $t(\mathrm{E})$, e.g., residential situation in case of a housing event, is represented by the node labeled State. Time Ago (F) and Time Ago (G) define the time ago certain types of changes $A$ and $B$, respectively had occurred the last time before $t$, such as for example a decrease or increase of family members for household event. Of course the general conceptual model could be extended with more classes, C, D etc. The History node represents for how many years back in the past information is available about that event for the person considered. This variable defines the range of the Time Ago variables in the sense that the time ago (from $t$ ) of the most recent event cannot be longer than the history. Finally the node Routing represents whether an event matrix in the survey was skipped or completed (as will be explained below).

The purpose of the model is to predict if an event will occur at a certain time $t$ (node Occurrence Event) based on the other nodes in the Bayesian Belief Network. We assume that both the existing state before time $t$ (State) and the last occurrence of an event (Time Ago) possibly influences the probability of the occurrence of an event on time $t$. If there is a (positive) effect of time, the probability of the occurrence of an event at time $t$ increases if an event of the same type occurred longer ago even after having taken the current state into account.

Constraints were included in the structure learning to prevent that directions of links are back-in-time. Fig. 1 illustrates those constraints as grey dashed lines with the crosses. There were also other constraints included for logical links; these are represented with dashed black lines in Fig. 1.

The nodes are described in general terms in the conceptual model. As an illustration, this paper describes results of a Bayesian Belief Network with two structural lifecycle events, change in residential location (in short 
housing) and change in household composition (in short household).

\section{DATA COLLECTION}

For this particular study various types of personal information is needed: structural lifecycle information, transport mode choice and personal characteristics. An Internet-based survey, administered at the end of 2004 [18], was designed to collect data for this study.

In total, 710 respondents completed the survey. The survey was designed to collect data concerning seven important structural lifecycle events: (a) Change in residential location, (b) Change in household composition, (c) Change in work location, (d) Change in study location, and (e) Change in car possession and availability, (f) Change in availability of public transport pass, and (g) Change in household income.

Respondents indicated whether they experienced these events, and, if so, they indicated in a matrix the timing of the event (month and year), the cause of the change (i.e., the specific type of event) that took place and the before and after situation for every change to a maximum of ten changes. In addition, respondents answered questions about their current situation in terms of personal and household characteristics, possession and availability of transport modes, their current travel behavior and their perception and preference of certain trip conditions.

\section{RESULTS AND ANALYSIS}

The computation time of the learning algorithm increases when the number of classes of variables increases. The size of the CPTs also expands if there are more classes involved. For these reasons and for a better comprehension of the network we reduced the number of classes of all variables to a maximum of four classes.

The states of each node in the learned Bayesian Belief Network (Figure 2) are described in the list below. The states of the history nodes are the same for each event.

\begin{tabular}{|c|c|c|c|}
\hline Nodes & Event & States & Description state \\
\hline \multirow{2}{*}{$\begin{array}{l}\text { History } \\
\text { nodes }\end{array}$} & & $1 / 2 / 3+$ years & \\
\hline & & not applicable & $\begin{array}{l}\text { If no information was } \\
\text { available }\end{array}$ \\
\hline \multirow[t]{2}{*}{$\begin{array}{l}\text { Time Ago } \\
\text { nodes }\end{array}$} & & $\begin{array}{l}1 / 2 / 3+\text { years } \\
\text { ago }\end{array}$ & \\
\hline & & Never & $\begin{array}{l}\text { type of change (A, B or } \\
\text { C) never occurred }\end{array}$ \\
\hline \multirow[t]{7}{*}{ State nodes } & & $\begin{array}{l}\text { Independent } \\
\text { (type A) }\end{array}$ & $\begin{array}{l}\text { person is living on his/her } \\
\text { own }\end{array}$ \\
\hline & Housing & $\begin{array}{l}\text { Student } \\
\text { (type B) }\end{array}$ & $\begin{array}{l}\text { person is living in a } \\
\text { student room }\end{array}$ \\
\hline & & $\begin{array}{l}\text { Parental (type } \\
\text { C) }\end{array}$ & $\begin{array}{l}\text { person is living with } \\
\text { his/her parents }\end{array}$ \\
\hline & \multirow{4}{*}{$\begin{array}{l}\text { House- } \\
\text { hold }\end{array}$} & 1 person & \multirow{4}{*}{$\begin{array}{l}\text { number of household } \\
\text { members }\end{array}$} \\
\hline & & 2 persons & \\
\hline & & 3 persons & \\
\hline & & $4+$ persons & \\
\hline
\end{tabular}

\begin{tabular}{|c|c|c|c|}
\hline \multirow[t]{2}{*}{ Routing } & & \multirow{2}{*}{$\begin{array}{l}\text { Completed } \\
\text { Skipped }\end{array}$} & \multirow{2}{*}{$\begin{array}{l}\text { Answered the question } \\
\text { Automatically skipped } \\
\text { this event question }\end{array}$} \\
\hline & & & \\
\hline \multirow{8}{*}{$\begin{array}{l}\text { Occurrence } \\
\text { Event } \\
\text { nodes }\end{array}$} & \multirow{4}{*}{ Housing } & No change & no occurrence a $t$ \\
\hline & & $\begin{array}{l}\text { Change, } \\
\text { independent } \\
\text { housing }\end{array}$ & $\begin{array}{l}\text { a change of type A } \\
\text { occurred a } t \text {, rent or buy a } \\
\text { house, living together etc. }\end{array}$ \\
\hline & & $\begin{array}{l}\text { Change, } \\
\text { student } \\
\text { housing }\end{array}$ & $\begin{array}{l}\text { a change of type B } \\
\text { occurred a } t \text {, move to first } \\
\text { student room, move to } \\
\text { another student room }\end{array}$ \\
\hline & & $\begin{array}{l}\text { Change, } \\
\text { parental } \\
\text { housing }\end{array}$ & $\begin{array}{l}\text { a change of type } \mathrm{C} \\
\text { occurred a } t \text {, move to } \\
\text { parental house }\end{array}$ \\
\hline & \multirow{4}{*}{$\begin{array}{l}\text { House- } \\
\text { hold }\end{array}$} & No change & no occurrence a $t$ \\
\hline & & $\begin{array}{l}\text { Change, } \\
\text { decrease } \\
\text { members }\end{array}$ & $\begin{array}{l}\text { a change occurred a } t \text {, for } \\
\text { example death, child or } \\
\text { other person moved out }\end{array}$ \\
\hline & & $\begin{array}{l}\text { Change, } \\
\text { increase } \\
\text { members }\end{array}$ & $\begin{array}{l}\text { a change occurred a } t \text {, for } \\
\text { example birth, child or } \\
\text { other person moved in }\end{array}$ \\
\hline & & $\begin{array}{l}\text { Change, same } \\
\text { members }\end{array}$ & $\begin{array}{l}\text { A change occurred a } t \text {, } \\
\text { the number of household } \\
\text { members stayed the same }\end{array}$ \\
\hline
\end{tabular}

The network structure is derived from the data of 648 respondents, who completed the relevant questions of the online survey. The whole network is empirically derived through structure and parameter learning using the NPC and EM algorithms in Hugin [13].

First, structure learning was used to determine the structure of the network that best fits the data. Decisions were made to keep or delete links from the ambiguous regions, which is part of the interaction with the user in the NPC algorithm. In order to decide which link should be kept in the ambiguous regions, the following priority order was assumed (from high to low priority):

1. links with gender, age, mode choice

2. links with Routing node and History node

3. links with the nodes State, Occurrence Event and Time Ago

4. links within one event before links between events

This corresponds to an order of decreasing independency of variables in our conceptual framework. After structure learning using the NPC algorithm, parameter learning was applied. The NPC algorithm was used for structure learning with the significance level set to 0.05 . Fig. 2 represents the learned Bayesian Belief Network. In total Hugin produced 39 links in this network. Besides the 11 constraints to predefine logical links in the network, Hugin learned 28 links between nodes. In a previous paper [20], four categories of relations were distinguished; (1) within event, across time periods; (2) between events during the same time period, (3) between events across time periods and (4) between an event and personal chararteristics or external variables.

Based on this learned network we can conclude that influences were detected among structural lifecycle events and between structural lifecycle events and external nodes.

The learned network represents among others direct and 


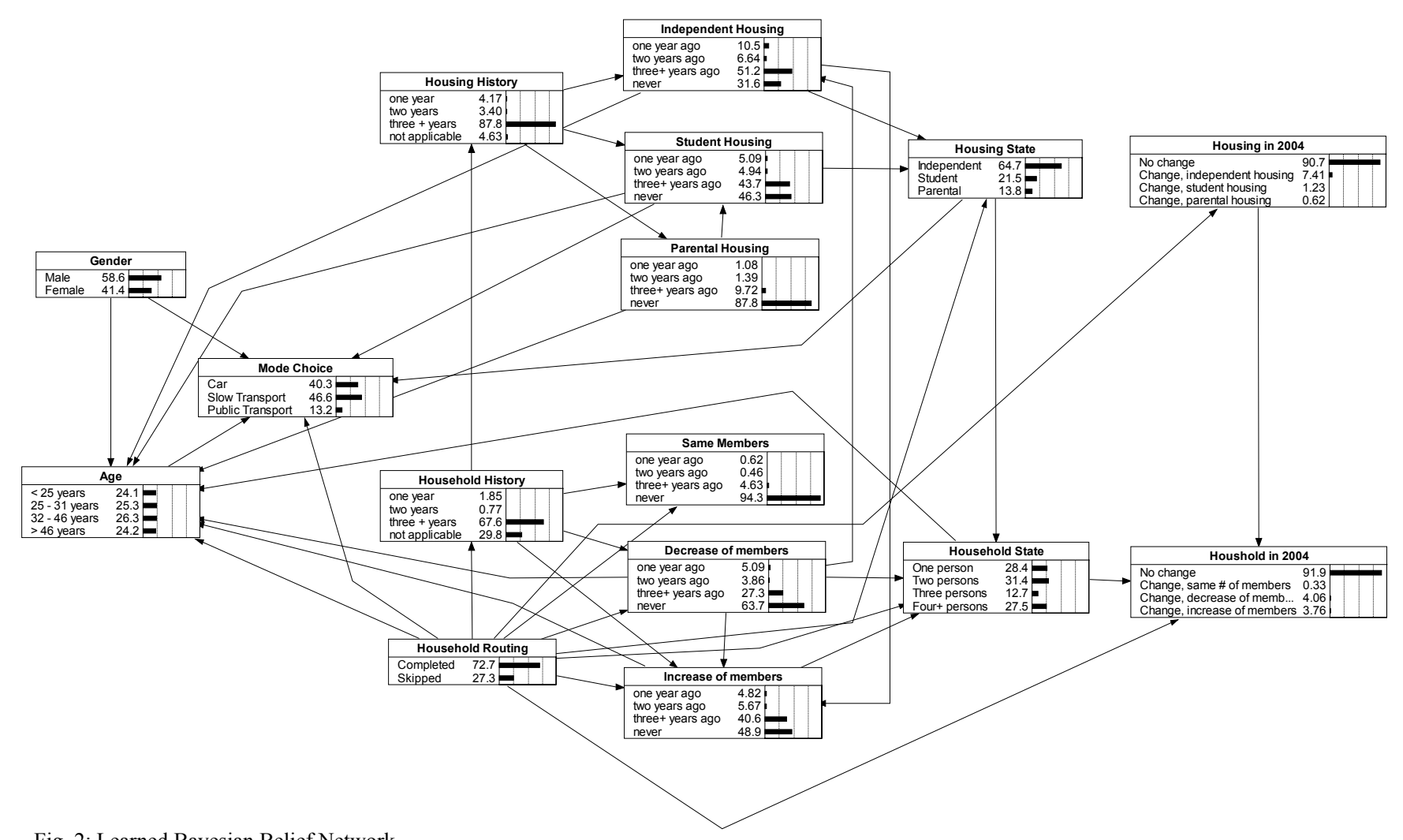

Fig. 2: Learned Bayesian Belief Network

indirect relations between the event change in residential location (housing) and the event change in household composition (household). The direct link between the node Housing 2004 and the node Household 2004 suggests that the occurrence of one event influences the occurrence of another event at the same time. Below we will describe some simulations. Simulation means entering hard evidence into the network, and reporting the changes in beliefs for certain nodes of interest. We are most interested in the nodes representing occurrence of Housing and Household events.

There is no direct link between Housing State and Housing 2004. Besides direct effects there are of course also indirect effects between nodes. As an example, the beliefs for the node Housing 2004 as a function of entered hard evidence for the node housing state are shown in Table I. The labels A, B, C, of Housing 2004 in Table I correspond respectively to new independent housing, new student housing; and new parental housing.

TABLE I

\begin{tabular}{|c|c|c|c|c|c|}
\hline & \multicolumn{4}{|c|}{ UPDATED BELIEFS HOUSING 2004} \\
\hline & & \multicolumn{4}{|c|}{ Housing 2004} \\
\hline & & No change & $\mathrm{A}$ & $\mathrm{B}$ & $\mathrm{C}$ \\
\hline & No evidence & 0,9074 & 0,0741 & 0,0123 & 0,0062 \\
\hline \multirow{3}{*}{ 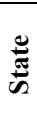 } & Independent & 0,9047 & 0,0919 & 0,0010 & 0,0024 \\
\hline & Student & 0,9115 & 0,0469 & 0,0297 & 0,0119 \\
\hline & Parental & 0,9137 & 0,0328 & 0,0387 & 0,0148 \\
\hline
\end{tabular}

The first row of Table I represents the beliefs of the node Housing 2004 when no evidence is entered to the network. Beliefs are automatically updated when evidence for certain nodes is entered to the network. The second row shows the updated beliefs with the evidence Independent for the node Housing State. The third and fourth row correspond with the updated beliefs of the node Housing 2004 given the evidence Student and Parental for the node Housing State, respectively.

As another example, Table II represents the beliefs for the node Household 2004 as a function of entered evidence of nodes Decrease of Members and Increase of Members (Time Ago).

TABLE II

UPDATED BELIEFS HOUSEHOLD 2004

\begin{tabular}{|c|c|c|c|c|c|}
\hline & \multicolumn{4}{|c|}{ Household 2004} \\
\hline & & $\begin{array}{l}\text { No } \\
\text { change }\end{array}$ & Same & Decrease & Increase \\
\hline & No evidence & 0,9186 & 0,0033 & 0,0406 & 0,0376 \\
\hline \multirow{4}{*}{ 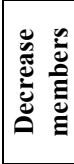 } & 1 year ago & 0,8814 & 0,0040 & 0,0451 & 0,0694 \\
\hline & 2 years ago & 0,8717 & 0,0048 & 0,0564 & 0,0672 \\
\hline & $3+$ years ago & 0,8878 & 0,0056 & 0,0522 & 0,0543 \\
\hline & Never & 0,9375 & 0,0021 & 0,0343 & 0,0260 \\
\hline \multirow{4}{*}{ 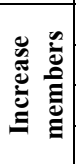 } & 1 year ago & 0,8521 & 0,0043 & 0,0713 & 0,0722 \\
\hline & 2 years ago & 0,8626 & 0,0044 & 0,0609 & 0,0722 \\
\hline & $3+$ years ago & 0,8789 & 0,0044 & 0,0691 & 0,0116 \\
\hline & Never & 0,9645 & 0,0022 & 0,0116 & 0,0218 \\
\hline
\end{tabular}

Table II shows that in some cases the probability of the occurrence of an (Household) event in 2004 increases if the last event of the same type happened longer ago, such as for example, in the second column - Same Members of Household 2004. 
TABLE III

UPDATED BELIEFS MODE CHOICE

\begin{tabular}{|c|c|c|c|c|}
\hline & & \multicolumn{3}{|c|}{ Mode Choice } \\
\hline & & Car & $\begin{array}{c}\text { Slow } \\
\text { Transport }\end{array}$ & $\begin{array}{c}\text { Public } \\
\text { Transport }\end{array}$ \\
\hline & No evidence & 0,4027 & 0,4656 & 0,1317 \\
\hline \multirow{3}{*}{ 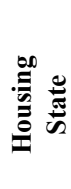 } & Independent & 0,4861 & 0,3875 & 0,1264 \\
\hline & Student & 0,1764 & 0,7301 & 0,0934 \\
\hline & Parental & 0,3651 & 0,4191 & 0,2159 \\
\hline
\end{tabular}

Table III represents the beliefs for the node Mode Choice as a function of entered evidence of Housing State. It suggest that the probability of choosing the car increases if agent live independently, and decreases when the housing state is "student".

\section{CONCLUSIONS}

In this paper, we have briefly discussed how a Bayesian network can be used to model and simulate life trajectory events and their effects on transport mode choice decisions. Given limited space only a few simulation results could be provided. We will complete this paper by discussing how this network will be incorporated into a agent-based simulation system. The start is a synthetic population of agents, representing individuals in the system. At every point in time, each agent has a set of states, which characterizes the agent along several dimensions at that point in time. Using the $\mathrm{BN}$, the probabilities of a particularly life trajectory event can then be predicted as a function of these states. Using Monte Carlo simulation, this defines the full set of states at every next point in time. Simultaneously, the $\mathrm{BN}$ is used to simulate in every time step any direct and indirect effects on transport mode availability and transport mode choices.

\section{REFERENCES}

[1] G. Rindsfuser and F. Klugl, "The scheduling agent using Sesam to implement a generator of activity programs," in Progress in ActivityBased Analysis, H. Timmermans, Ed. Amsterdam, pp. 115-137, 2005.

[2] T.A. Arentze, F. Hofman, and H.J.P. Timmermans, "Deriving rules from activity diary data: a learning algorithm and results of computer experiments", Journal of Geographical Systems, Springer, 2001.

[3] T.A. Arentze, and H.J.P. Timmermans, "Modeling learning and adaptation processes in activity-travel choice: A framework and numerical experiment", Transportation 30: 37 - 62, 2003

[4] T.A. Arentze, and H.J.P. Timmermans, "A learning-based transportation oriented simulation system", Transportation Research Part B Methodological, Vol. 38, 2004.

[5] D. Charypar and K. Nagel, "Generating complete all-day activity plans with genetic algorithms", Transportation 32: 369-397, 2003

[6] T.A. Arentze, and H.J.P. Timmermans, "Information Gain, Novelty Seeking and Travel: a Model of Dynamic Activity-Travel Behavior under Conditions of Uncertainty", Transportation Research A, 2005

[7] M. Balmer, K. Nagel and B. Raney, "Large scale multi-agent simulations for transportation applications," Proc. Beh. Responses to ITC, Eindhoven (CD-Rom), 2004.

[8] R.J. F. Rossetti and R. Liu, "An Agent-Based Approach to Assess Drivers' Interaction with Pre-Trip Information Systems", Journal of Intelligent Transportation Systems, 9:1, 1 - 10, 2005.
[9] G. Hertkort and P. Wagner, "Adaptation of time use patterns to simulated travel times in a travel demand model," in Progress in Activity-Based Analysis, H. Timmermans, Ed. Amsterdam, pp. 161$174,2005$.

[10] P.J.H.J. van der Waerden, A.W.J. Borgers, and H.J.P. Timmermans, "Key events and critical incidents influencing transport mode choice switching behavior: an exploratory study", Proceedings $82^{\text {nd }}$ Annual Meeting of the Transportation Research Board), January 12-16, Washington, D.C., (CD-Rom: 13 pp.), 2003.

[11] P.J.H.J. van der Waerden, A.W.J. Borgers, and H.J.P. Timmermans, "The influence of key events and critical incidents on transport mode choice switching behaviour: a descriptive analysis", Proceedings of the IATBR Conference, Lucerne, August 10-16 (CD-Rom: 24 pp.), 2003.

[12] J. Pearl, Probabilistic Reasoning in Intelligent Systems: Networks of Plausible Inference, Morgan Kaufmann Publishers Inc., San Francisco, CA, 1988.

[13] Hugin Expert A/S (1995-2005), Software program, Aalborg, Denmark.

[14] P. Sprites, C. Glymour, R. Scheines, D. Heckerman, C. Meek, and G.F. Cooper, Causation, Prediction and Search, MIT Press, $2^{\text {nd }}$ edition, 2000.

[15] A.L. Madsen, M. Lang, U.B. Kjærulff, and, F. Jensen, "The Hugin Tool for Learning Bayesian Networks", Computer Science, Volume 2711, 594-605, 2004

[16] S.L. Lauritzen, "The EM algorithm for graphical association models with missing data", Computational Statistics \& Data Analysis, 19: 191 $-201,1995$.

[17] R.G. Cowell, and A.P. Dawid, "Fast retraction of evidence in a probabilistic expert system", Statistics and Computing, 2: 37 - 40, 1992.

[18] M. Verhoeven, T.A. Arentze, H.J.P. Timmermans, and P.J.H.J. van der Waerden, "Modeling the Impact of Key Events on Long-Term Transport Mode Choice Decisions: A Decision Network Approach Using Event History Data", Transportation Research Record, 1926, pp. 106-114, 2005.

[19] M. Verhoeven, T.A. Arentze, H.J.P. Timmermans, and P.J.H.J. van der Waerden, "Examining Temporal Effects of Lifecycle Events on Transport Mode Choice Decisions", Proceedings CUPUM Conference, London 2005.

[20] M. Verhoeven, T.A. Arentze, H.J.P. Timmermans, and P.J.H.J. van der Waerden, "Modeling the Influence of Structural Lifecycle Events on Transport Mode Choice Decisions Using a Structure Learning Algorithm", paper presented at the 11th International Conference on Travel Behaviour Research, Kyoto, August 2006.

[21] H. Steck and V. Tresp, "Bayesian belief networks for data mining", Proceedings of The 2nd Workshop on Data Mining und Data Warehousing als Grundlage moderner enscheidungsunterstuetzender Systeme, DWDW99, Sammelband, Universität Magdeburg, 1999.

[22] Q. Han, T.A. Arentze, H.J.P. Timmermans, D. Janssens and G. Wets, "Modelling the Dynamic Formation of Activity Location ChoiceSets", Proceedings WCTR Conference, Berkeley 2007. 